\title{
POR UMA REVISÃO DAS HIPÓTESES SOBRE OS CENTROS DE ORIGEM E ROTAS DE EXPANSÃO PRÉ-HISTÓRICAS DOS TUPI*
}

\author{
Francisco S. Noelli**
}

\begin{abstract}
"Mas então", ousei comentar, "estais ainda longe da solução..." "Estou pertíssimo", disse Guilherme, "mas não sei de qual." "Então não tendes uma única resposta para vossas perguntas?" "Adso, se as tivesse ensinaria teologia em Paris."

"Em Paris eles têm sempre a resposta verdadeira?"

"Nunca", disse Guilherme, "mas são muito seguros de seus erros."

"E vós", disse com impertinência infantil, "nunca cometeis erros."

"Freqüentemente", respondeu. "Mas ao invés de conceber um único erro imagino muitos, assim não me torno escravo de nenhum." (U. Eco, O Nome da Rosa)
\end{abstract}

A motivação deste artigo surgiu ao longo de uma leitura da bibliografia arqueológica, etno-histórica, lingüística e etnográfica sobre os falantes das línguas do tronco Tupi. Deveu-se, também, à constatação de uma carência de informações e de domínio do conjunto da bibliografia

\footnotetext{
* Uma versão preliminar deste artigo foi publicada no Boletim da ABA (Noelli, 1993a).

** Bolsista recém-Mestre - FAPERGS.
} 
Tupi nos trabalhos que trataram das hipóteses referentes ao centro de origem e às rotas de expansão.

O tema é fundamental à História e Etnologia da América, pois a expansão dos Tupi foi um dos maiores movimentos humanos de expansão geográfica. As proporções da distribuição geográfica e, principalmente, da homogeneidade ${ }^{1}$ cultural dos Tupi foram raras. Diante das informações históricas e arqueológicas, pode-se verificar que mudanças drásticas só ocorreram após a chegada dos europeus no século XVI.

Por Tupi, designa-se um Tronco Lingüístico que engloba aproximadamente 45 línguas que se espalharam, há vários milênios, pelo leste da América do Sul (Brasil, Peru, Bolívia, Paraguai, Argentina e Uruguai). Por Tupi são designados também os povos falantes dessas línguas. Das 45 línguas, as mais citadas desde a chegada dos europeus foram o Guarani e o Tupinambá. Apesar da aceitaçāo da organização lingüística feita por Aryon Rodrigues (1950, 1958, 1964, 1984-1985, 1986), o termo Tupi tem sido usado, indevidamente, para designar a língua Tupinambá. A expressão Tupi-guarani, que define uma das nove Familias Lingüísticas do Tronco Tupi, também vem sendo usada erroneamente para designar uma língua, em algumas publicações.

A expansão dos povos falantes das línguas do tronco Tupi foi o alastramento de grupos com uma base cultural comum, considerada nos aspectos lingüísticos, sociais, comportamentais, materiais, tecnológicos, simbólicos, etc. O grupo que deu origem a esta expansão dividiu-se, e os grupos resultantes, enquanto distanciavam-se especialmente, sofreram diferenciações que, entretanto, não chegaram ao ponto de apagar sua base comum.

A Lingüística é a ciência que vem estabelecendo com maior consistência a unidade subjacente aos Tupi. A cultura material vem sendo mais lentamente estudada por arqueólogos e etnólogos, que já conseguiram resultados consideráveis para alguns grupos. Embora a cultura material esteja mais sujeita às alterações devidas aos contatos interétnicos, entre os Tupi notam-se evidentes semelhanças e uniformidades materiais, técnicas, formais, funcionais e de nomenclatura. Em diversos pontos do leste da América do Sul, desde o início da invasão européia os cronistas chamaram atenção a essas semelhanças e uniformidades. Posteriormente, os cientistas procuraram explicar como os Tupi ocuparam tão vasta área geográfica e mantiveram sua base cultural comum. 
Desde a década de 1830, formularam-se hipóteses propondo centros de origem e rotas de expansão dos Tupi. Porém, a maioria dos pesquisadores não justificou sua hipótese sobre o centro de origem, embasando-a em deduçōes puramente lógicas, a partir de características lingüísticas, físicas (raciais), materiais e geográficas (Câmara Jr., 1979a; Edelweiss, 1947). Alguns utilizavam estas características isoladamente e outros todas em conjunto. Os autores mais antigos empregavam os termos sociedades, civilização, etnia e povo, como sinônimo de cultura. Elementos rigorosos de pesquisa só foram introduzidos após 1960, com métodos arqueológicos, empregando datas $\mathrm{C}^{14}$, e lingüísticos, estudando relações entre línguas do tronco Tupi.

O objetivo deste artigo é uma apresentação das propostas, hipóteses e conclusões a respeito do centro de origem e rotas de expansão dos falantes das línguas do tronco Tupi. As motivações religiosas da "busca da terra sem mal", analisadas nos últimos 80 anos, desde a hipótese de Nimuendajú (1914), seguida por Métraux (1927, 1928), Schaden (1945, 1954), Queiróz (1973), Clastres (1975), assim como o enfoque ecológico do yvy marane'y (abandonando o viés da 'busca da terra sem mal"), inicialmente por Melià $(1981,1987)$ e, posteriormente, por Schaden (1982), Martínez (1985) e Brochado (1989), serão tratados no futuro.

$\mathrm{Na}$ maioria dos trabalhos, os antropólogos enfocaram os motivos religiosos e os arqueólogos estudaram a distribuição geográfica das cerâmicas, considerando-as indicadores de rotas de expansão. Os dois grupos raramente trocaram informaçôes. indevidamente definiram todos os movimentos populacionais como migraçōes. Porém, é necessária uma terminologia mais adequada para essas movimentações, que ocorreram em dois momentos distintos: um anterior e outro posterior aos contatos com os europeus.

Quando houve contatos, em seguida ocorreram desestruturações e conflitos em diversos níveis, obrigando muitos dos grupos Tupi a abandonar suas aldeias. O termo preciso para estas mudanças é migração, significando etimologicamente, em sua origem latina, movimento saindo de um lugar para outro, abandonando sua região de origem. É possível que este tipo de mudança tenha ocorrido antes dos europeus, por força de conflitos com outros nativos da América do Sul.

Para os deslocamentos ditados pelo ritmo do aumento demográfico e por diversas modalidades sociopolíticas de fracionamento das aldeias, 
que resultaram no paulatino afastamento do centro de origem em diversas direçōes, o termo etimologicamente mais preciso é o de expansão, significando distensão, alargamento, alastramento, com o sentido de ir conquistando novas áreas sem abandonar as antigas. Isto permitiu, por exemplo, que entre o baixo Amazonas e São Paulo os Tupinambá mantivessem a posse da maior parte do litoral brasileiro e partes vizinhas do interior por vários séculos até a chegada dos europeus. Os Guarani, da mesma forma, mantiveram extensos territórios nas bacias do Paraguai, Paraná, Uruguai e litoral sul brasileiro. Sobre os demais falantes das línguas do tronco Tupi não há ainda informações consistentes a este respeito.

\section{POR UM CENTRO DE ORIGEM: HIPÓTESES}

"se novas comunidades, resultantes da divisão do que foi antes uma só comunidade com uma só língua, distanciam-se no espaço geográfico e perdem de todo o contato entre si, desaparece inteiramente a necessidade de ajuste comunicativo ente elas" (Rodrigues, 1986:18).

Isto implica, com o passar do tempo, a formação de línguas diferenciadas, que se desdobrarão ou não em outras que poderão manter traços comuns. Assim, teremos uma língua original (proto-língua), que originará o Tronco e seus futuros desdobramentos divididos em Famílias e Línguas. Um determinado nível de relacionamento léxico e estrutural faz com que se classifique estas línguas como pertencentes à mesma família. Um nível ainda menor agrupa as línguas como descendentes do mesmo tronco (Swadesh, 1971; Camara Jr., 1979b). Tem sido considerado "centro de origem", "terra natal", "berço", o local onde se aglomera o maior número de famílias lingüísticas de um tronco (Dyen, 1956).

A Lingüística oferece maiores garantias para estabelecer relaçōes entre grupos do que a Etnografia, pois a língua é "um fenômeno social, que constitui um objeto independente do observador, e para o qual se possuem longas séries estatísticas" (Lévi-Strauss, 1967:73). Neste estudo as informações etnológicas têm peso menor, garantindo o reconhecimento das áreas de chegada e elementos para comparações materiais, para constatar continuidade e mudanças. A explanação etnográfica mais aprofundada, procurando verificar a complexidade das expansões Tupi, 
foi realizada por Susnik (1975). Quando há somente informações sobre o ponto de chegada e sobre o que se supõem serem partes das rotas percorridas e dominadas, as hipóteses mantêm-se especulativas.

A relação filogenética entre línguas de um tronco pode ser feita independentemente da localização geográfica dos falantes. Mas, quando há elementos suficientes, a abordagem geográfica e as deduções sobre locais de origem passam a ter um caráter rigoroso. Atualmente, a abordagem mais consistente nas interpretações das expansões é propiciada pelas relações entre a Língüística e a Arqueologia (Ehret, 1976). Parte-se do princípio de que um determinado conjunto de características arqueológicas marcaria grupos de falantes de uma determinada língua, ou língua estreitamente aparentadas. Utilizando tais relações, a localização dos sítios arqueológicos permite o mapeamento preciso do território de domínio de uma língua, desde seu ponto de chegada, historicamente conhecido, até seu ponto de partida pré-histórico. Isto pode ser verificado nos casos Guarani e Tupinambá (Brochado, 1984) e Aruák e Caribe (Rouse, 1985). Desta forma, através do conteúdo dos sítios arqueológicos, pode-se verificar as continuidades e as mudanças entre os Tupi.

A proposta inaugural para o centro de origem dos Tupi foi elaborada por Alcides D’Orbigny em 1839, na primeira síntese etnológica da América do Sul, desenvolvida a partir de idéias de Alexandre von Humboldt. Partindo de critérios lingüísticos, físicos e de localização geográfica dos falantes do tronco Tupi, sugeriu uma região entre o Paraguai e o Brasil como "pátria primitiva” (D' Orbigny, [1839] 1944:37, 368). Denominando os Tupi como "Brasílio-Guarani" ou "Guarani”, D' Orbigny também inaugurou uma confusão que demorou a ser esclarecida: a concepção de que entre os Tupi incluiam-se os falantes do tronco Karíb.

Seguindo D' Orbigny, Karl F. Ph. von Martius (1867:177-9) propôs um centro de origem entre o Paraguai e o sul da Bolívia, considerando esta a possível região de entrada humana no leste da América do Sul, descendo os Andes. Martius acreditava que a expansão fora recente, pouco antes da chegada dos europeus e que, desde antes de 1500, de "longa data", já estavam no caminho da degeneração, sugerindo que as altas culturas eram anteriores às tribais (Martius, 1867; no primeiro capítulo, trata demoradamente do tema). A partir da idéia de que as populações nativas da América passaram por um contínuo processo de decadência, deduziu a existência de várias línguas derivadas de umas poucas originais. As 
derivações seriam originárias de uma desordenada mistura entre grupos distintos, resultando em novas línguas e dialetos. Esta posição é o desenvolvimento das hipóteses publicadas em 1831 (Spix \& Martius, 1831) e 1845, no artigo "Como se deve escrever a História do Brasil" (Martius, 1845).

Dezenove anos após Martius, Karl von den Steinen (1886:353) sugeriu, sem justificativa, que as cabeceiras do rio Xingu estavam na área "onde mais ou menos se encontra o ponto geográfico central da irradiação Tupi". Von den Steinen (1886:323) foi o criador do termo Tupi-guarani. Embora não tenha justificado sua criação, pode-se inferir que teve o objetivo de eliminar a confusão das discussões da sua época, quando se chamavam os Tupi ora de "tupi" ora de "guarani" (discussão do problema In: Edelweiss, 1947).

Paul Ehrenreich (1891), membro da segunda expedição de von den Steinen ao Xingu em 1887, munido de argumentações lingüísticas e etnográficas mais explicitas que seus predecessores, dizia que "tudo indica que devemos procurar seu ponto de êxodo onde ainda hoje vemos aglomerada a massa mais compacta destas tribos, isto é, no Paraguai e suas vizinhanças". Dizia também que a "distribuição muito espalhada destes povos, como se verá examinando um mapa, explica-se pela irradiação de um centro" (Ehrenreich, 1891). Em Ehrenreich nota-se a continuidade das hipóteses sobre centro de origem de D' Orbigny e Martius, e sobre irradiação central de von den Steinen. Será nestes quatro cientistas que grande parte dos demais pesquisadores embasarão suas proposiçôes.

Affonso A. de Freitas (1914) propõe como centro de origem a regiāo situada entre as cabeceiras do rio Madeira, lago Titicaca, rios Beni e Araguaia. Foi severamente criticado por Baldus (1954:251-252).

Em 1922 Rodolfo Garcia (1922), baseado em Ehrenreich, coloca a área entre as bacias dos rios Paraguai e Paraná como provável centro de origem.

Fritz Krause (1925) propôs uma região aproximada à dos Omágua e Kokáma, entre os rios Napo e Juruá, como centro de origem. Krause foi o primeiro pesquisador a propor o centro de origem dentro da Amazônia, e apenas Métraux (1928:302) citou-o.

Entre todos, Alfred Métraux (1927, 1928, 1948a, 1948b) teve maior projeção, sendo o mais citado e quase não tendo contestadas suas 
proposiçōes a respeito do centro de origem e rotas de expansão. A notável imunidade de algumas das suas proposições mantém-se (Cf. Fausto, 1992; Laraia, 1988; Porro, 1993:74-76; Rodrigues, 1990; Santos, 1992), apesar da existência de diversas provas arqueológicas e lingüísticas que as tornaram ultrapassadas. Por exemplo, a hipótese de que teria havido uma "Guaranização" (assimilação da língua ou de palavras) de grupos, como os "Chané, Tapieté, Guayaki, etc", através da introdução da língua ou de palavras, tornou-se obsoleta diante das recentes análises lingüísticas que demonstraram que, ao invés de terem sido "Guaranizadas", eram línguas da mesma família (Métraux, 1928:8-9; Cf. Rodrigues, 1984-85).

Embora o seu primeiro trabalho de fôlego tenha tratado das migrações históricas dos $\mathrm{Tupi}^{3}$ (Métraux, 1927), foi no estudo sobre a cultura material que propôs sua hipótese sobre o centro de origem (Métraux, 1928). Comparando geograficamente elementos materiais e tecnológicos, deduziu que o berceau original seria uma "região suficientemente vizinha" da Amazônia, porque os Tupi apresentam influências setentrionais e Amazônicas (Métraux, 1928:310). Assim, Métraux supôs que, dificilmente, a margem norte do Amazonas seria a "pátria primitiva", e que o centro de origem estaria em algum lugar da bacia do Tapajós ou do Xingu. Por fim, definindo-se, concluiu que

"nenhuma tribo Tupi-guarani de importância na época pré-histórica estaria estabelecida sobre a margem esquerda do Amazonas e que a ocupação de sua costa seria feita tardiamente, nos forçando portanto a colocar o centro de dispersão das tribos desta raça dentro da área limitada ao norte pelo Amazonas, ao sul pelo Paraguai, ao leste pelo Tocantins e ao oeste pelo Madeira" (Métraux, 1928:312).

Branislava Susnik (1975:57), apesar da ampla revisão bibliográfica, sem justificativas e fugindo à "regra", sugeriu as planícies colombianas como centro de origem.

O segundo grande grupo de estudiosos a propor centros de origem foi constituído por lingüístas, também baseados em D' Orbigny, Martius, von den Steinen e Ehrenreich.

Guillermo Bertoni $(1916,1922)$ acreditava na existência de uma única língua de "Guarani" o tronco Tupi e, confusamente, dizia que a origem dos Tupi era asiática, vindo para a América já formados 
culturalmente. Bertoni (1922:298), reproduzindo Max Uhle, afirmou que os Tupi tiveram influência direta das altas culturas mexicanas e centro-americanas.

Paul Rivet (1924), influenciado por Martius e Ehrenreich, após comparar diversas línguas, proporia o centro de origem entre os rios Paraguai e Paraná, na altura do Paraguai. Rivet foi seguido por Jorge B. Stella (1928), Mansur Guérios (1935), Aryon Rodrigues (1945) e J. Alden Mason (1950). Wilhelm Schmidt (1913) propôs um centro de origem mais para o oeste do Paraguai, próximo dos altiplanos bolivianos.

Independentemente, outros lingüístas propuseram como centros de origem: A. Childe (1940) - cabeceiras do Xingu e alto Araguaia -; Cestmir Loukotka $(1929,1935,1950)$ - entre o Juruena e o Arinos -; Ernest Migliazza (1982) - entre o Ji-Paraná e Aripuanã, tributários do rio Madeira; Greg Urban (1992) - para o tronco Tupi, entre o Madeira e o Xingu, mais próximo das cabeceiras do que das várzeas e, exclusivamente para a família Tupi-guarani, entre o Madeira e o Xingu.

O terceiro grande grupo a propor hipóteses para um centro de origem é composto por arqueólogos. É necessário esclarecer que há duas hipóteses distintas no presente, ambas utilizando a cerâmica como indicador básico para o centro de origem: a) uma postula que a cerâmica foi criada fora da Amazônia a ali introduzida posteriormente; b) outra, que a cerâmica foi inventada dentro da Amazônia e difundida para o resto da América a partir de lá.

A primeira etapa da pesquisa arqueológica a respeito das origens está relacionado às comparações entre cerâmicas, onde procuraram verificar as relações da cerâmica dos Tupinambá e dos Guarani com as da Amazônia (Netto, 1885; Torres, 1911, 1934; Linné, 1925; Costa, 1934; Howard, 1947, 1948; Willey, 1949). Neste período as influências de Martius e Métraux em Samuel Lothrop (1932) e Gordon Willey (1949), são perceptíveis embora não explícitas, principalmente nas hipóteses de dispersão tardia e centros de origem na bacia do médio Paraná. Angyone Costa (1934; mapa VI), sob as mesmas influências, sugeriu a região central do Mato Grosso como centro de origem.

A questão dos centros de origem sob o ponto de vista arqueológico recebeu destaque nos anos 60 , com a instalação do PRONAPA ${ }^{4}$, cujo objetivo era acumular dados para elaborar uma seqüência cultural e reconhecer as direções de influências, migração e difusão (Evans, 1967:9). 
Entretanto, baseado em premissas ${ }^{5}$ de pesquisas anteriores (Meggers, 1951, 1954, 1957, 1963; Meggers \& Evans, 1957; Silva \& Meggers, 1963), o PRONAPA postulava a invenção da cerâmica fora da Amazônia e a decadência cultural causada pelo ambiente adverso da floresta tropical. A similaridade com as hipóteses e conclusões de Martius e Métraux era clara, apesar de não citadas. Nos cinco anos do PRONAPA, há três sínteses gerais (Brochado et al, 1968; Meggers, 1985; PRONAPA, 1970) e duas a respeito da Tradição "Tupiguarani" (Brochado, 1973; Meggers \& Evans, 1973).

É importante destacar que o PRONAPA sugeriu que se deixasse de empregar as centenárias designações etnográficas para os vestígios arqueológicos (Guarani e Tupinambá), propondo que:

“Após a consideração de possíveis alternativas, não obstante suas conotações lingüísticas, foi decidido rotular como 'Tupiguarani' (escrito numa só palavra) esta tradição ceramista tardiamente difundida, considerando já ter sido o termo consagrado pela bibliografia e também a informação etno-histórica estabelecer correlação entre as evidências arqueológicas aos falantes de língua Tupi e Guarani, ao longo de quase todo o litoral brasileiro". (Brochado et al, 1969:10; PRONAPA, 1970:12).

O conceito "Tradição Tupiguarani" (Terminologia, 1969:8 e 1976: 146), baseado na proposição de Willey \& Phillips (1958:22), foi estabelecido como:

“(...) uma tradição cultural caracterizada principalmente por cerâmica policrômica (vermelho e ou preto sobre engôbo branco e ou vermelho), corrugada e escovada, por enterramentos secundários em urnas, machados de pedra polida e pelo uso de tembetás".

Nesta abordagem, eliminou-se o uso tradicional das informações etno-históricas e lingüísticas, passando-se a empregar exclusivamente as da Arqueologia. Iniciou um período de esquecimento das diferenças de identidades e de cultura material reconhecidas entre os Tupi, enquadrando-se numa única categoria grupos historiamente conhecidos tanto por suas igualdades, como por suas diferenças e oposições. Reeditou-se, para aspectos arqueológicos, a indevida unificação que havia sido feita no 
século XIX entre grupos distintos. Esta confusão foi possível devido à profunda similaridade entre os tipos de superfície das cerâmicas. Por outro lado, foi privilegiada a análise da composição da pasta e não a relação entre forma e uso das vasilhas, abundantemente descritas nas crônicas e dicionários dos séculos XVI e XVII. A consideração da funcionalidade e da forma teria remetido diretamente ao elenco das diferenças, enquanto que a pasta não é um demarcador suficiente.

Brochado (1973) localizou geograficamente os sítios, interpretado as 55 datas $\mathrm{C}^{14}$ do PRONAPA, mais 7 por termoluminescência obtidas no Projeto Paranapanema em São Paulo, admitindo o centro de origem proposto por Métraux e sugerindo rotas principais de expansão.

Meggers, baseada nos dados do PRONAPA e nas suas proposições do início dos anos 60 (Meggers, 1963), propôs como centro de origem a base dos Andes, na Bolívia (1972:129). No ano seguinte, Clifford Evans, baseando-se em Métraux (1927) e Rodrigues (1958), desloca a "terra natal" dos Tupi para a planície amazônica, a leste do rio Madeira (fronteira Brasil/Bolívia), onde concentrava-se o maior número de famílias lingüísticas do tronco Tupi (Meggers \& Evans, 1973:57). Posteriormente, Meggers reiterou sua segunda hipótese (Meggers, 1975, 1976, 1979, 1982; Meggers \& Evans, 1978:Figs. 7 e 8; Meggers, Dias, Miller \& Perota, 1988:Fig. 5). Entre os arqueólogos, Meggers foi seguida por Pedro I. Schmitz (1991), que se baseou lingüisticamente em Migliazza (1982) para marcar o centro de origem, as expansões e a temporalidade. Magalhães (1993) mesclou as propostas de Loukotka com as rotas de expansão de Meggers.

Donald Lathrap (1970) sugere como centro de origem dos Tupi a confluência do rio Madeira com o Amazonas. Suas hipóteses foram influenciadas por Métraux, apesar de não citá-lo e, explicitamente, por Rodrigues (1958). Lathrap propõe que a cerâmica teria sido inventada dentro da Amazônia, contrariando a tradiçâo inaugurada por D' Orbigny. Brochado, abandonando os pressupostos que tinha utilizado no PRONAPA, adotou e ampliou as hipóteses de Lathrap (Brochado, 1984, 1989, 1991; Brochado \& Lathrap, 1980). Meggers \& Evans (1973), em resposta a Lathrap, argumentam com a impossibilidade da cerâmica ter sido inventada dentro da Amazônia e da cerâmica policrônica ter relações com os proto-Tupi, porque ainda não havia provas arqueológicas Tupi na Amazônia. 
Recentemente Ondemar Dias (1993), ao revisar as propostas de Schmitz (1991) e Brochado (1984), desconsiderou a produção científica existente, principalmente das relações internas da família lingüística Tupi-guarani, propôs São Paulo como o centro de origem dos Tupi.

Claristella Santos (1991, 1992), ao discutir as abordagens que sintetizam resultados lingüísticos e arqueológicos, também desdenhou os antecedentes da produção científica sobre as expansões Tupi e desconsiderou a complexidade da questão, centrando sua análise em aspectos puramente lógicos.

\section{AS ROTAS DE EXPANSĀO: A BUSCA DOS CAMINHOS DOS TUPI}

A identificação das rotas pré-históricas depende, exclusivamente, da localização dos sítios arqueológicos deixados pelo movimento de expansão. Os assentamentos históricos marcam apenas os pontos finais da expansão. As "migrações históricas" estudadas por Métraux (1927) representam movimentos de fuga de pressão européia e não expansões, como foi originalmente sugerido.

Recentemente, a direção das expansões tem sido deduzida a partir da localização geográfica dos grupos históricos ou através do mapeamento dos sítios arqueológicos e das datações radiocarbônicas.

Quase todos os proponentes de centros de origem postularam rotas de expansão, quase sempre sem justificativas demonstráveis e desconsiderando o conjunto das pesquisas. Há dois grupos de propostas: a) os que seguiram D' Orbigny, ou a expansão de sul para o norte; b) os partidárioss de Ehrenreich, ou da expansão radial.

D' Orbigny sugeriu que uma porção dos Tupi teria se dirigido até a região de Buenos Aires, a partir de uma área entre Paraguai e Brasil. Posteriormente, outra porção teria ido para os Andes (Chiriguanos). Finalmente, sem fazer ligações com as suas sugestões citadas, concluiu que "somente os Guarani", se se considera sua cunha o Trópico de Capricórnio, haviam desenvolvido de sul a norte suas migrações" (D' Orbigny, 1944:37).

Martius (1867:7-10), seguindo e desenvolvendo D' Orbigny, postulou que a partir do Paraguai, a rota dos Tupi teria seguido primeiro para 
o sul e depois para o norte do Brasil: "Provavelmente da região entre o Uruguai e o Paraná, chegando até o litoral da Bahia, Pernambuco e as matas Amazônicas". Martius, jamais citado pelos arqueólogos profissionais, aparece implicitamente em Meggers e nos que a seguiram. Apesar de não ter sido um profissional, Costa (1934: mapa VI) seguiu Martius e foi o único que o citou.

Ehrenreich (1891), observando a disposição geográfica dos Tupi, sugeriu que a "dispersão radial" deu-se em sucessivas ondas, para o norte, leste e sul. Porém, seguindo D' Orbigny e Martius, repetiu que os que chegaram ao sul teriam, a seguir, se deslocado para o norte ao longo do litoral atlântico. O modelo de expansão radial foi seguido por Métraux (1928), que influenciou Lathrap (1970) e Brochado (1984, 1989), seguidos por Scatamacchia (1990). Os três últimos não adotaram a sugestão da rota sul-norte, nem jamais citaram Ehrenreich.

As rotas de expansão só começaram a ter uma conformação embasada empiricamente no início dos anos 70. Apesar de ter a geografia dos sítios e datas $C^{14}$, Brochado (1973) detalhou um esquema "migratório" para as regiões de atuação do PRONAPA acatando também as direções já propostas por D' Orbigny e Martius.

Brochado (1973:17) sugeriu que a expansão dos "Tupiguarani" teria se dado em duas "ondas migratórias": uma pré-histórica e outra que se desenvolveu até depois da chegada dos europeus. A primeira onda representava a Subtradição Pintada e a segunda a Subtradição Corrugada. Após os contatos com os europeus, a Subtradição Corrugada teria passado por uma transição, sendo substituída pela Subtradição Escovada. Estas subtradiçōes caracterizam-se, em seu conjunto cerâmico, pela predominância de um tipo de acabamento de superfície em relação a outros (Terminologia, 1969:7, 1976:143). Posteriormente, em diversos congressos científicos, Brochado refutou completamente a possibilidade da existência destas ondas, afirmando que as diferenças quantitativas entre acabamentos de superfície eram relativas à função dos recipientes cerâmicos (Brochado, 1989; Brochado, Monticelli \& Neumann, 1990; Brochado \& Monticelli, 1991).

Meggers \& Evans (1973) usaram o mesmo esquema de Brochado, estabelecendo as rotas a partir do centro de origem que sugeriam, em direção ao sul do Brasil e depois para o norte (Meggers, 1972:129, 1975, 
1976, 1982; Meggers \& Evans, 1973, 1978: Figs 7-8; Meggers, Dias, Miller \& Perota, 1988: Fig. 5).

Lathrap (1970: Fig. 5) cruzando dados arqueológicos, lingüísticos e etnográficos, já havia empregado a idéia de expansão radial, baseado na disposição geográfica dos Tupi. Embora seu modelo tenha sido muito sintético e dedutivo, publicou uma hipótese que influenciaria propostas fora do esquema corrente entre os pesquisadores. Sua hipótese inaugurou uma era de polarização política, com uma discussão sobre a origem da cerâmica e da agricultura fora ou dentro da Amazônia. Sua metodologia de campo não foi muito diferente da dos pronapianos, embora fosse movido por concepções teóricas distintas.

A hipótese de Lathrap foi adotada no final da década de 1970 por Brochado, que aprofundou o tema, enfocando as rotas de expansão a partir do conjunto mais completo de informações e variáveis publicadas. Também enfatizou que há condiçōes para uma interdisciplinaridade frutíferà entre os dados lingüísticos, arqueológicos e etnográficos Tupi.

Brochado (1984:28-39) procurou estabelecer relações entre as possíveis divisōes do tronco Tupi, desde sua origem (Proto-Tupi) até a formação das línguas e dialetos históricos, com o modelo de evolução e diferenciações das cerâmicas amazônicas proposto por ele e Lathrap (Brochado \& Lathrap, 1980). Após observar as divisões do Proto-Tupi (Cf. Rodrigues, 1964; Lemle, 1971), verificou as correspondências entre as cerâmicas e as famílias lingüísticas conhecidas, sendo algumas mais consistentes e outras menos, considerando que o desenvolvimento material e lingüístico foi concomitante (as maiores consistências foram definidas nos casos Guarani e Tupinambá).

Brochado (1984) concluiu que o aparecimento do proto-Tupi teria sido resultado de uma divisão entre grupos produtores das cerâmicas da Tradição Guarita (da Tradição Policrômica Amazônica), em alguma região da Amazônia Central. Para Brochado, a diferenciação das línguas e das cerâmicas ao longo de diferentes expansōes resultaria da separação espaço-temporal do proto-Tupi, causadas por pressões populacionais contínuas devidas a uma exploração demográfica dentro da Amazônia. Desta divisão, as correlações mais evidentes ligam os Guarani às cerâmicas encontradas no oeste da Amazônia e os Tupinambá às cerâmicas do leste amazônico. Sugeriu que as expansōes se desenrola- 
ram em dois momentos: a) primeiro, ao longo dos principais cursos fluviais; b) segundo, com o aumento da pressão demográfica, colonizando os afluentes de grandeza decrescentes (Brochado, 1984).

Estas colonizações teriam, no caso Guarani, um sentido do norte para o sul, desde a Amazônia até a foz do Prata, pelos cursos dos rios Paraná, Paraguai e Uruguai (há sítios desde Corumbá até Buenos Aires). Para leste, no caso dos Tupinambá, saindo pela foz do Amazonas e seguindo pelo litoral até São Paulo e, também, entrando para o interior pelos rios que desaguam no Atlântico. Ao longo dos principais rios as populações se expandiram e, regidas pelo aumento demográfico, dominaram sucessivamente os rios de grandezas menores.

Em colaboração com Lathrap (Brochado \& Lathrap, 1980), concluiu que a diferenciação da cerâmica Guarani em relação à tradição Guarita, manifestou-se pela perda de técnicas decorativas como o modelo, a excisão e a incisão em linhas finas e largas, ocorridas durante as expansōes para fora da Amazônia, em direção sul, pelos rios Madeira e Guaporé. Teriam desaparecido, também, as tijelas com bordas extrovertidas e reforçadas, assim como as flanges labiais e mediais onde antes se encontravam a decoração. Do contato com portadores das cerâmicas do leste boliviano e peruano, surgiram novas formas de panelas e jarras: conoidais, com contorno infletido ou complexo, marcado pelo desenvolvimento do bojo e/ou pela segmentação horizontal, corrugadas ou pintadas, utilizadas secundariamente como urnas funerárias. Estes são os traços característicos da cerâmica dos Guarani arqueológicos e históricos. Características destas formas e técnicas são encontradas no sudoeste da Amazônia meridional, entre os falantes das línguas da família Pano (Cf. Myers, 1990:99-142).

Ainda não há resultados arqueológicos no baixo Amazonas, mas apenas dados lingüísticos e históricos, podendo-se deduzir que os Tupinambá deslocaram-se para o leste, pelo médio curso até sair pela sua foz do Amazonas, colonizando o litoral até o Trópico de Capricórnio. A cerâmica Tupinambá possui algumas características formais derivadas do estilo Marajoara e de outras formas do baixo Amazonas, preservando quase todas as vasilhas abertas, inclusive as de boca ovalóide e quadrangulóide. Não possui, porém, a maioria das formas fechadas, principalmente as antropomórficas. A decoração também foi descaracterizada, perdendo-se as técnicas de incisão, excisão e modelagem, 
conservando a pintura policrômica concentrada nas bordas extrovertidas e reforçadas (Brochado \& Noelli, m.s.).

Brochado demonstrou através de comparações formais e decorativas, que a cerâmica Tupinambá não poderia ter se desdobrado e evoluído fora da Amazônia, próximo do Paraguai, como foi proposto originalmente no século passado. Nem se dispersado primeiro em direçâo ao sul e, posteriormente, ao norte do Brasil, como sugeriu Meggers ao reproduzir os modelos do século passado.

As relações lingüísticas publicadas após 1984 demonstram ser impossível que os Tupinambá tivessem colonizado o leste da América do Sul, desde o Paraguai até o sul do Brasil e depois em direção ao nordeste/norte. Considerada a mais antiga língua da família Tupi-guarani (Jensen, 1989:13), o Tupinambá nāo poderia derivar do Guarani, cujos falantes eram os únicos ceramistas Tupi ao sul de São Paulo. O modelo de Brochado recebeu um reforço significativo depois que Rodrigues (1984-1985, 1986) apresentou os primeiros resultados a respeito das relações internas na família Tupi-guarani. As relações entre o Tupinambá e o Kokáma são parte da chave explicativa, podendo servir para corroborar a tese de Brochado. O Kokáma e o Tupinambá possuem características que estão ausentes nas línguas da família Tupi-guarani da Bacia do Paraná e dos afluentes a sudoeste do Amazonas, dando consistência à hipótese de Brochado de que a rota Tupinambá teria iniciado na Amazônia e seguido pelo litoral Atlântico até São Paulo. Os Guarani, partindo dos afluentes ao sul do Amazonas, dirigiram-se para o Brasil centro-oeste e meridional pela Bacia do Paraná até Buenos Aires.

A esta questão lingüística soma-se outro elemento: Uma das maiores dificuldades para derivar a cerâmica Tupinambá da Guarani seria explicar como, ultrapassando o Paranapanema, na sugerida difusão do sul para norte, a cerâmica Guarani teria se transformado tẫo drasticamente, incluindo completas inversões da forma e decoração?

Brochado procurou retomar a individualidade das cerâmicas relacionadas a cada um dos grupos falantes das línguas do tronco Tupi, eliminando o impreciso conceito "Tupiguarani". Tendo a cerâmica, os dados etno-históricos e a lingüística como referência, retomou o antigo conceito da arqueologia Guarani, denominando-a Subtradição Guarani. Sugeriu o nome Subtradição Tupinambá para os Tupinambá do litoral 
brasileiro, assim como para os demais Tupi (não-Tupinambá) anteriormente enquadrados no "Tupiguarani" (Brochado, 1984).

Desde 1984 Brochado vem propondo, com critérios semelhantes, outra divisão. Para os falantes do Tupinambá, exclusivamente, o conceito de Subtradição Tupinambá, com a intenção de diferenciá-los dos demais Tupi. Os demais Tupi, falantes de línguas da família Tupi-guarani, assim como os das outras seis famílias do tronco lingüístico e das três línguas isoladas, continuam, ainda, arqueologicamente classificados como "Tupinambá". Os que se expandiram pelo Brasil central, norte, nordeste e Peru, deverão aguardar por pesquisas arqueológicas nas suas áreas. Ou esperar por resultados obtidos em áreas historicamente conhecidas, em publicações que aguardam edição.

Considerando que o tema é incipiente, Brochado acredita que foi importante ter conseguido organizar um modelo que refletisse o conjunto de todas informações sobre os Tupi, escapando ao modelo tradicional apoiado, majoritariamente, em deduçōes lógicas (Brochado, com. pessoal. 1992).

A recente hipótese de expansão proposta por Greg Urban (1992:92-93), a partir de Rodrigues e de Lemle, conecta mais explicitamente a derivação lingüística com a expansão geográfica. Apesar das informações arqueológicas, Urban empregou exclusivamente as lingüísticas. Desconsiderou, entretanto, alguns problemas já resolvidos pelo estudo inicial das relações internas entre as línguas da família Tupiguarani desenvolvido por Rodrigues (1984-1985).

Urban liga as expansões a dois momentos sucessivos, com duas magnitudes crescentes em termos de distanciamento do centro de origem. Entre 3 e 5 mil anos atrás, o primeiro momento correspondente à divisão inicial e expansão do tronco Tupi (denominado por ele como MacroTupi) numa área do Brasil centro-oeste, entre o Madeira e o Xingu, até o Amazonas, com maior concentração e diversidade em Rondônia (Urban, 1992:92). Não mais associado à expansão Tupi, conforme Urban, o segundo momento corresponde à grande expansão geográfica da família Tupi-guarani, dividida em três fases consecutivas. Baseando-se em Rodrigues $(1958,1964)$, repete que teria sido entre dois ou três mil anos. Sugere, também, que parte da expansão "é provavelmente muito recente" (Urban, 1992:92). 
Supondo que a família Tupi-guarani iniciou sua expansão "em algum lugar entre o Madeira e o Xingu", pareceu-lhe evidente que os Kokámas e os Omágua se deslocaram até o Amazonas na primeira derivação da família. "Pela mesma época", os Guaiaki foram para o sul, atingindo o Paraguai, e os Siriono para o sudoeste até a Bolívia. Este momento foi seguido pelos falantes das línguas mais próximas dos não-Tupi-guarani: os Pauserna e Kawahib (Parintintín) a oeste, os Kayabi e Kamayurá ao longo do Xingú; os Xetá ao sul do Brasil; os Tapirapé, Tenetehara e, talvez, com os Wayampi se deslocando à frente até as Guianas, foram para próximo da foz do Amazonas (Urban, 1992:92).

Por volta do ano mil, a terceira fase marcou a expansão dos falantes do Chiriguano e Guarayo para a Bolívia, do Tapieté e Guarani para o Paraguai, dos "Kaingwa" na área entre o Paraguai, Argentina e Brasil, e, finalmente, dos Tupinambá, Tupiniquins e Potiguara na costa do Brasil até a foz do Amazonas. Supõe, também, que estas línguas formariam, originalmente, uma única, denominada "Tupi-guarani, que não deve ser confundida com a família mais ampla" (Urban, 1992:92).

Urban ao citar que teria havido uma língua chamada Tupi-guarani, fez emergir uma antiga discussão de nomenclatura já resolvida no final da década de 40. Tupi-guarani, desde a década de 1940, corresponde a uma família lingüística e, nunca, a um língua (Edelweiss, 1947:3-9; Loukotka, 1950; Rodrigues, 1945, 1950). Caso Urban tivesse adcionado "Proto" ao termo Tupi-guarani, seria menos problemático, pois estaria se referindo à língua que deu origem às atuais da família Tupi-guarani. Os "Tupiniquins e Potiguara" desde 1950 são considerados como dialetos do Tupinambá (Rodrigues, 1950:101-102). Urban também repete a questão das derivaçōes mais recentes, "por volta do ano 1000 ", desconsiderando as datas $\mathrm{C}^{14}$ que serão apresentadas abaix. Por fim, Urban apresenta mais uma falha quando trata dos "Kaingwa" ("os do mato", Cf. Melià, Saul \& Muraro, 1987:362). Estes, eram falantes do Guarani não integrados às reduções jesuíticas ou às sociedades coloniais.

\section{A TEMPORALIDADE DAS EXPANSÕES TUPI}

Dois tipos de datações foram empregadas: absolutas $\left(\mathrm{C}^{14} \mathrm{e}\right.$ termo-luminiscência) e relativas (seriações cerâmicas e glotocronologia). 
As seriações não serão consideradas na análise, por não representarem um meio preciso de dataçāo.

As datas glotocronológicas, propostas por Rodrigues (1958, 1964), são: o proto-Tupi, língua que originou as componente do tronco Tupi, teria se constituído por volta de 5000 anos atrás e a família Tupi-guarani, 2500 anos depois. Esta data, para a família Tupi-guarani, está ultrapassada devido ao fato de os Guarani já estarem ocupando o Paraná e o Rio Grande do Sul há 2000 anos atrás e os Tupinambá há 1800 anos atrás o Piauí. Apesar de estarem publicadas desde o início dos anos 70, os lingüistas não vêm considerando as datas $\mathrm{C}^{14}$ em suas análises ou na reprodução da proposta de Arnyon Rodrigues em 1958/1964 (Cf. Migliazza, 1982; Greenberg, 1987; Urban, 1992). As porcentagens glotocronológicas, atualmente em desuso, devem ser comparadas e reavaliadas face às datações radiocarbônicas.

Existem cerca de 70 datas por $\mathrm{C}^{14}$ e termoluminescência publicadas, posteriores ao Anno Domini, na Bacia Amazônica, Bacia do ParanáParaguai, litoral atlântico e nos rios costeiros (Brochado, 1973, 1984, 1989:72; Brochado \& Lathrap, 1980). Os sítios arqueológicos reconhecidos chegam aos 2200 .

As datas são muito mais antigas do que imaginavam os etnólogos que propuseram uma expansão rápida e próxima da chegada dos europeus. $\mathrm{O}$ motivo destas propostas estava apoiado na uniformidade de diversos aspectos culturais já apontados, pois eles acreditavam que a uniformidade somente era possível devido à pouca antigüidade do distanciamento entre os Tupi. Como se verá adiante, não foi avaliada a possibilidade de comportamentos prescritivos.

Apesar de serem poucas em relação ao número de sítios, e desigualmente distribuídas entre as áreas de ocupação Tupi, as datas $\mathrm{C}^{14}$ demonstram que a expansão não foi recente como supuseram muitos. Relacionadas com outras variáveis, as datas $\mathrm{C}^{14}$ possuem elementos para projetar a expansão para antes dos 2500 anos propostos por Rodrigues.

Em três regiōes há datas próximas ao Anno Domini: Santa Maria $\mathrm{RS} \pm 150$ D.C; médio rio Ivaí $-\mathrm{PR} \pm 100$ D.C; São Raimundo Nonato-PI \pm 260 D.C. Tanto no extremo sul do Brasil como no nordeste, portanto afastados dos centros de origem propostos, as datações atestam a antigüidade das expansões e das divisões lingüísticas. Na Argentina, Uruguai, Paraguai e Bolívia há poucas datas, todas posteriores ao século 
X (Brochado, 1984). No Perú e áreas brasileiras vizinhas, as cerâmicas relacionadas aos Kokámas, Omágua e Kokamíya ainda estão por ser melhor pesquisadas (Lathrap, 1970; Myers, 1990).

Em outros dois pontos existem datações próximas das mais antigas: em Santa Maria-RS \pm 475 D.C., médio rio Ivaí-PR \pm 460 D.C. e \pm 570 D.C., podendo demonstrar a consistência das mais antigas. A seguir, aumenta o número de datas próximas do presente, em diversos pontos do leste da América do Sul. No litoral sudeste e nordeste do Brasil temos: Curimatú-RN \pm 800 D.C., Cricaré-ES \pm 895 D.C., Guaratiba-RJ \pm 980 D.C. (Brochado, 1973, 1984).

Pode-se verificar que os Tupi já estavam espalhados pelo Brasil (Rio Grande do Sul e Piauí) há 1900 anos atrás, em áreas muito distantes entre si e dos centros de origem propostos.

Neste contexto, totalmente aberto às novas informações, é necessário considerar a quantidade de pesquisa e os resultados por região, no leste da América do Sul. Lembra-se que houve mais pesquisa e datações no Brasil meridional, além das escassas pesquisas dentro da Amazônia. Estas diferenças quantitativas influenciaram as contribuições dos que seguem o modelo D' Orbigny-Martius, principalmente Meggers e seus seguidores.

\section{CONCLUSÕES}

A questão do centro de origem dos Tupi continua em aberto, tendo sido tratada introdutoriamente nesta publicação, enquanto aguarda o desenvolvimento de novas pesquisas. Considero as conclusões abaixo como provisórias.

O conjunto de dados arqueológicos e lingüísticos tende a aproximar o possível centro de origem Tupi à margem sul do médio Amazonas (Cf. mapas in: Brochado, 1984; Nimuendajú, 1981). Esta aproximação deve-se às características lingüísticas e arqueológicas dos Tupi constatadas recentemente (Rodrigues, 1984-1985; Brochado, 1984; Brochado \& Lathrap, 1980).

1) As ligações da cerâmica Tupinambá com as formas do baixo Amazonas e as ligações da cerâmica Guarani com as do sudoeste da Amazônia, especialmente com a dos Pano. 
2) As relações lingüísticas entre o Tupinambá e o Kokáma, com detalhes que não ocorrem nas línguas das Bacias do Madeira-ParanáParaguai, revelando a impossibilidade de derivações das duas primeiras a partir das últimas, isto é, do sul para o norte.

Sobrepondo estas duas características e verificando todas as variáveis implicadas, pode-se vislumbrar uma tripartiçâo espacial entre os Tupi na região amazônica ocorrida após as derivaçōes do proto-Tupi, que resultaram nas línguas Tupinambá, Kokáma e Guarani. Nesta tripartição, provisoriamente, ficam em segundo plano as áreas de domínio das demais línguas da família Tupi-guarani, assim como das familias Arikém, Jurúna, Mondé, Mundurukú, Romaráma, Tupari e das línguas Tupi isoladas. Este segundo plano deve-se às lacunas arqueológicas e lingüísticas, ainda em pesquisa. Porém, devido aos atuais elementos conhecidos dos grupos citados abaixo, estas lacunas não afetam as conclusões que seguem.

A respeito das rotas de expansão, o modelo proposto por Brochado (1984) é o mais consistente e bem argumentado, se observarmos o conjunto de hipóteses analisadas neste trabalho. Considerando as localizações dos sítios arqueológicos e as dos Tupi históricos, observa-se: os Tupinambá no baixo Amazonas, litoral brasileiro e partes do interior das regiōes Norte, Nordeste e Sudeste do Brasil; os Kokámas no Solimões; os Guarani na Bacia do Paraná-Paraguai de Corumbá a Buenos Aites, no Rio Grande do Sul e litoral sul do Brasil. Os demais Tupi encontram-se no centro-oeste do Brasil, Rondônia, Bolívia e Paraguai.

A distribuição geográfica dos Tupi, como notou originalmente Ehrenreich (1891) e as associações entre as relações lingüísticas e cerâmicas, sugerem uma expansão radial a partir do centro de origem. Não uma expansão para o sul e depois para o norte como deduziram, sem as mesmas provas da atualidade, D' Orbigny, Martius e seus seguidores.

A ausência de informaçôes Tupi em certas áreas do Amazonas pode dever-se à expansão de falantes de outras línguas (mapa de Nimuendajú, 1981). Os cacicados não-Tupi, que necessitam ser mais estudados, possivelmente se expandiram após os Tupi, causando seccionamentos em várias regiōes. A escassez de pesquisas arqueológicas no médio e baixo Amazonas, norte do Pará, Maranhão e Ceará, também pode ser um fator que influi na atual concepção de que haveriam espaços desocupados pré-historicamente pelos Tupi. 
A posição dos Guarani, em relação aos Kokámas e Tupinambá do Amazonas, forma uma longa perpendicular que se estende de Corumbá até Buenos Aires (de Corumbá para o norte ainda não há informações). Desta perpendicular saem diversas linhas que entram pelo Brasil, pelos afluentes do Paraná e Uruguai, alcançando o litoral em alguns pontos dos Estados sul-brasileiros. A oeste da grande perpendicular, ocorrem entradas no Paraguai e Bolívia.

A expansão dos Tupi, diante do atual conjunto de informações lingüísticas, etnográficas, etno-históricas e arqueológicas, foi uma lenta e paulatina conquista de territórios. O termo "enxameamento", sugerido por Brochado (1989:80), define como teria sido a mola mestra da expansão:

"Ao mesmo tempo que se movimentavam, os Tupi realimentavam sua própria pressão populacional, pela expansão nas férteis várzeas dos rios maiores ou nas planícies costeiras, o que exigia a ocupação de novas áreas, até que todos os ecossistemas possíveis de serem explorados tenham sido ocupados. (...) no sentido de que as regiōes de onde saíram não ficaram vazias, pelo contrário, a população continuava crescendo até o ponto de obrigar a saída de novas vagas (...) $\mathrm{O}$ sistema de adjudicação e a vida cerimonial dos grupos locais Tupi só eram efetivos para manter a coesão até um certo tamanho da população".

A expansão parece ter, algumas vezes, simplesmente expulsado ou eliminado os povoadores não-Tupi que os antecederam. Outras vezes, pode ter assimilado porções de comunidades que sucumbiram diante de sua pressão expansionista. Alguns estudos recentes apontam para grandes distâncias genéticas e ação de fatores dispersivos entre os Tupi, que poderiam atestar assimilações de outros grupos (Salzano \& Callegari-Jacques, 1991). As grandes distâncias genéticas poderiam ser testadas em esqueletos de um mesmo sítio arqueológico, em nível local, ou, em grande escala, entre todos os esqueletos reconhecidos.

Diante disto e das relações etnográficas e lingüísticas estabelecidas entre os Tupi, a "Guaranização" sugerida por Métraux (1928:7-8) está superada. Os três grupos citados por Métraux (Tapieté, Chané, Guayaki) não eram "guaranizados", mas parentes lingüísticos próximos dos Guarani, conforme a análise de Rodrigues (1984-1985). 
O passo necessário a seguir, deve ser em direção ao esclarecimento do que ocorreu com a maioria dos outros grupos Tupi, que se expandiram em escala bem menor que os Guarani e Tupinambá, principalmente, entre o Madeira e o Tocantins. Este é um espaço pouco conhecido pela Arqueologia, que no futuro poderá dar definitivamente o roteiro inicial das expansões, encerrando a era das especulações e hipóteses puramente lógicas.

$\mathrm{O}$ aprofundamento das pesquisas comparativas entre os Tupi, para que se possa conhecer em maior detalhe suas igualdades e diferenças é outro ponto importante numa futura agenda de projetos (Cf. Viveiros de Castro, 1984-1985).

Novas abordagens devem ser incorporadas à busca das rotas de expansão e centro de origem, aproveitando a abundância de informações já existentes e, principalmente, a continuidade entre o período préhistórico e histórico. Do ponto de vista da longa duração braudeliana (Braudel, 1978), esta continuidade, relativizada, permite que se possa estudar consistentemente fatos sociais ligados às áreas de interesse arqueológico. Permite, também, que se possa inferir, em alguns grupos Tupi, continuidade ou mudança de certos aspectos comportamentais, tecnológicos, econômicos, etc.

Com as novas abordagens, deve-se procurar o que está por trás da manutenção e proximidade de tantos elementos culturais, em áreas tão distantes. As datas $\mathrm{C}^{14}$ derrubaram a crença estabelecida no século XIX, de que a semelhança cultural Tupi era resultado de uma "rápida e tardia" expansão, próxima da chegada dos europeus.

A noção de prescritividade conceituada por Sahlins (1990:13) deveria ser incorporada às pesquisas, pois considera aquelas sociedade com a ordem vigente, mesmo quando o que acontece não tiver precedentes. Seria o que Florestan Fernandes ([1964] 1975:35) já havia escrito sobre a educação dos Tupinambá, que parece exemplificar a educação entre os Tupi, que visaria a perpetuar a ordem social estabelecida: "ela não visa a preparar o homem para a 'experiência nova'; mas a prepará-lo para conformar-se aos outros' '. A prescritividade, ao que tudo indica, não só fazia com que os Tupi repetissem milenarmente diversos aspectos de cultura (artefatos, tecnologia, língua, alimentação, etc), como influiria diretamente nas estruturas de parentesco e alianças. 
A nova abordagem das expansōes também deve analisar aspectos ainda não plenamente considerados, como a demografia e a influência do manejo ambiental na mudança da sede dos assentamentos. A demografia influía diretamente na divisão das aldeias e no ritmo da expansão. Juntamente com o aumento demográfico, as relações de parentesco e as alianças teriam ditado as regras de divisão dos grupos locais. Concomitantemente ao crescimento demográfico, o manejo agroflorestal ditaria um ritmo expansivo ainda mais lento do que conceberam os pesquisadores. Além das plantas típicas da roça, os Tupi manejavam um largo número de vegetais que só podiam ser aproveitados depois de muitos anos de seu plantio (Noelli, 1993b).

No passado, com o aumento gradativo da pressão demográfica dos Tupi, assim como dos não-Tupi de regiōes vizinhas, a tendência de mudar a sede da aldeia deveria ter sido menor do que as constatadas após a chegada dos europeus.

\section{AGRADECIMENTOS}

Este texto foi intensamente debatido com José Brochado, Fabíola Silva e Felipe Escosteguy. Evidentemente, a discussão é de minha inteira responsabilidade.

\section{NOTAS}

1. Obviamente há diferenças, que ainda não foram profundamente estudadas (cf. Viveiros de Castro, 1984-1985).

2. O mapa de Nimuendajú (1981) mostra a localização histórica dos Tupi.

3. Em 1927-28 o Tronco Tupi nāo havia sido definido linguisticamente, sendo genericamente chamado por Métraux de Tupi-guarani.

4. Programa Nacional de Pesquisas Arqueológicas, 1965-1970. Continuado na Amazônia Legal Brasileira a partir de 1977, como PRONAPABA, Programa Nacional de Pesquisaas Arqueológicas da Bacia Amazônica (cfr. análise geral in: Alves, 1991; Noelli, 1993).

5. Atualmente ultrapassadas (Morán, 1990; Roosevelt, 1991a, b, 1992).

6. Por Guarani, D’Orbigni designava a totalidade dos Tupi. 


\section{BIBLIOGRAFIA CITADA}

ALVES, Cláudia. A cerâmica pré-histórica no Brasil: Avaliação e Proposta. Clio, série arqueológica, Recife, v. 1, n. 7, p. 9-88, 1991.

BALDUS, Herbert. Bibliografia critica da etnologia brasileira. São Paulo: Comissão do IV Centenário da Cidade de Sâo Paulo. 1954.

BERTONI, Moisés S. Influencia de la Lengua Guaraní en Sud-América y Antillas. Anales Cientificos Paraguayos, série II, v. 1, p. 1-120, 1916.

. La Civilizacion Guarani. Parte I. Puerto Bertoni: Ex Sylvis. 1922.

BRANDÃO, Carlos R. Os Guarani: Índios do sul - religião, resistência e adaptação. Estudos Avançados, São Paulo, v. 4, n. 10, p. 53-90, 1990.

BRAUDEL, Fernand. História e Ciências Sociais. A longa duração. In: BRAUDEL, Fernand. Escritos sobre a história. Tradução de Jacó Guinsburg et Tereza C. S. da Mota. São Paulo: Perspectiva, 1978. p. 41-78.

BROCHADO, José P. Migraciones que difundierón la tradición alfarera Tupiguarani. Relaciones, Buenos Aires, v. 7, p. 7-39, 1973.

. An Ecological Model of the Spread of Pottery and Agriculture Into Eastern South America. Urbana-Champaign: University of Illinois at Urbana-Champaign, 1984. (PhD tesis).

- A expansẫo dos Tupi e da cerâmica da tradição policrômica amazônica. Dédalo, São Paulo, v. 27, p. 65-82. 1989.

- Um modelo de difusão da cerâmica e da agricultura no leste da América do Sul. Anais do I Simpósio de Pré-história do Nordeste Brasileiro, Recife. CLIO, série arqueológica, v. 4 , p. $85-8,1991$.

BROCHADO, José P.; CALDERÓN, Valentín; CHMYZ, Igor; DIAS, Ondemar; EVANS, Clifford; MARANCA, Sívia; MEGGERS, Betty J.; MILLER, Eurico Th.; NASSER, Nássaro; PEROTA, Celso; PIAZZA, Walter; RAUTH, José \& SIMÕES, Mário. Arqueologia Brasileira em 1968. Belém: Museu Paraense Emílio Goeldi, 1969.

BROCHADO, José P.; LATHRAP, Donald. Amazonia. (datil.), 1980.

BROCHADO, José P.; MONTICELLI, Gislene; NEUMANN, Eduardo. Analogia etnográfica na reconstrução gráfica das vasilhas Guarani arqueológicas. Veritas, Porto Alegre, v. 35 , n. 140 , p. $727-43,1990$.

BROCHADO, José P.; MONTICELLI, Gislene. Reconstrução gráfica da cerâmica Guarani por comparação com vasilhas inteiras. Apresentado na VI Reunião Científica da Sociedade de Arqueologia Brasileira, 1991.14p. (datilografado).

BROCHADO, José P.; NOELLI, Francisco S. Relaçōes entre as cerâmicas Marajoara e Tupibambá. (datil.).

CAMARA JR.; Joaquim M. Introdução ds línguas indigenas brasileiras. Rio de Janeiro: Ao Livro Técnico, 1979a.

.Princípios de lingǘtstica geral. 6. ed. Rio de Janeiro: Padrão, $1979 \mathrm{~b}$.

CHILDE, A. Étude philologique sur les noms du "chien" de l' antiquité jusqu' à nos jours. Arquivos de Museu Nacional, Rio de Janeiro, v. 39, p. 5-498, 1940.

CLASTRES, Hélène. La terre Sans Mal; le prophetisme Tupi-guarani. Paris: Éditions du Seuil, 1975.

COSTA, Angyone. Introdução à Arqueologia Brasileira. São Paulo: Nacional, 1934. 
DIAS, Ondemar. Consideração a respeito dos modelos de difusão da cerâmica Tupiguarani no Brasil. Apresentado na IX Reunião Científica da Sociedade de Arqueologia Brasileira, 1993. 14 p. (datilografado).

D' ORBIGNY, Alcides. El hombre americano considerado en sus aspectos fisiológicos y morales. Traducción de Alfredo Cepeda. Buenos Aires: Editorial Futuro, 1944.

DYEN, Isidore. Language distribution and migration theory. Language, Baltimore, v. 32, p. $611-26,1956$.

EDELWEISS, Frederico. Tupis e Guaranis - Estudos de etnonímia e lingüistica. Salvador: Museu do Estado da Bahia, 1947.

EHRENREICH, Paul. Die Einteilung und Verbreitung der Volkerstamme Brasilienses nach dem gegenwartigen Stande unsrer Kennthisse. Patermanns Mitteilungen, v. 37, p. 81-91, 114-24, Göthingen, 1891.

EHRET, Christopher. Linguistic evidence and its correlations with archaeology. World Archaeology, v. 8, n. 1, p. 5-18, 1976.

EVANS, Clifford. Introdução. PRONAPA 1. Publicações Avulsas, Museu Paraense Emilio Goeldi, Belém, v. 6, p. 7-12, 1967.

FAUSTO, Carlos. Fragmentos de história e cultura Tupinambá. Da etnologia como instrumento crítico de conhecimento etno-histórico. In: CUNHA, Manuela Carneiro da (org.). História dos índios no Brasil. São Paulo: FAPESP/SMC/Cia. das Letras, 1992, p. 381-96.

FERNANDES, Florestan. Notas sobre a educação na sociedade Tupinambá. Petrópolis: Vozes, 1975. p. 33-83.

FREITAS, Affonso A. de. Distribuição geográfica das tribos indígenas na época do descobrimento. Revista do Instituto Histórico e Geográfico de São Paulo, v. 19, p. 103-128, 1914.

GARCIA, Rodolfo. Ethnographia indigena. Diccionario Histórico, Geographico, e Ethnographico do Brasil. Introdução Geral. I. Rio de Janeiro: Imprensa Official, 1922. p. 249-77.

GREENBERG, Joseph. Language in the Americas. Stanford: Stanford University Press, 1987.

GUÉRIOS, Rosário F. M. Novos rumos da Tupinologia. Separata da Revista do Círculo de Estudos Bandeirantes, Curitiba, v. 1, n. 2, 12 p.

HOWARD, George D. Prehistoric ceramic styles of lowland South America, their distribution and history. New Haven: Yale University Publications in Anthropology, n. 17, p. 5-95, 1947.

. Northeast Argentina. In: HOWARD, George D. \& GORDON, R. Willey. Lowland Argentine Archaeology. New Haven: Yale University Publications in Archaeology, n. 19, p. 9-24, 1948.

JENSEN, Cheryl J. J. O Desenvolvimento histórico da língua Wayampi. Campinas: Editora da UNICAMP, 1989.

KRAUSE, Fritz. Beitrage zur Ethnographie des Araguaya-Xingu-Gebietes. Actés du XXI Congrés International des Américanistes. Goteborg, p. 67-79, 1925.

LARAIA, Roque B. O movimento constante do povoamento indígena no Brasil. Humanidades, v. 5, p. 104-9, 1988.

LATHRAP, Donald. The Upper Amazon. Ancient Peoples and Places. London: Thames and Hudson, 1970. 
LEMLE, Miriam. Internal classification of the Tupi-guarani linguistic family. In: DAVID, Bendor-Samuel (Ed.). Tupi Studies, Norman: Summer Institute of Linguistics, v. 1, p. 107-9, 1971.

LÉVI-STRAUSS, Claude. A análise estrutural em lingüística e em antropologia. In: LÉVISTRAUS, Claude. Antropologia estrutural, Rio de Janeiro: Tempo Brasileiro, 1967. p. 45-70.

LENNÉ, Sigwald. The Tecnique of South Americam Ceramics. Göteborg, Göteborgs kungl. Vetenskaps-och Vitterhets-Samhalles Handlingar, 1925.

LOTHROP, Samuel K. Indians of the Paraná Delta, Argentina. Annals of the New York Academy of Science, New York, v. 32, p. 77-232, 1932.

. Le setá, un nouveau dialecte tupi. Joumal de la Societé des Américanistes, Paris, n. 21, 373-98, 1929.

. Línguas indígenas do Brasil. Revista do Arquivo Municipal, São Paulo, v. 54, p. 147-74, 1935.

LOUKOTKA, Cestmir, Les langues de la famillie Tupi-guarani. Boletim $n^{\circ} 16$ de Etmografia e Línguas Tupi-guarani da Faculdade de Filosofia, Ciências e Letras da Universidade de São Paulo. São Paulo, 1950.42 p.

MAGAlHÃES, Erasmo D. O Tupi no litoral. Revista de Arqueologia, São Paulo, v. 7, p. 51-67. 1993.

MARTINEZ, Noemí D. La migration Mbya (Guarani). Dédalo, São Paulo, v. 24, p. 147-169. 1985.

MARTIUS, Karl F. Ph. Como se deve escrever a História do Brasil. Revista Trimensal de Historia e Geographia ou Jomal do Instituto Historico e Geographico Brazileiro, Rio de Janeiro, v. 6, p. 389-411. 1845.

. Beitrage zur Ethographie und Sprachangenkunde Sudamerika's zumals Brasiliens. v. I: Zur Ethnographie. Leipzig: Friederich Fischer, 1867.

MASON, J. Alden. The languages of South American Indians. In: STEWARD, Julian (Ed.). Handbook of South American Indians, Washington, Smithsonian Institution, v. 6, p. 157 $317,1950$.

MEGGERS, Betty J. A pre-columbian colonization of the Amazon. Archaeology, New York, v. 4 , n. 2 , p. $110-4,1951$.

. Environmental limitation on the development of culture. American Anthropologist. n. 56, p. 801-24, 1954.

- Environment and culture in the Amazon Basin: an appraisal of the theory of environmental determinisme. Studies in Human Ecology. Washington: The Pan American Union, 1957.

- Cultural development in Latin America: an interpretative overview. In: Betty Meggers and Clifford Evans (Eds.). Aboriginal Cultural Development in Latin America: an Interpretative Review. Washington: Smithsonian Institution, 1963. p. 131-45.

. Prehistoric America. Chicago: Aldine Publishing Press, 1972.

. Application of the biological model of diversification to cultural distributions in Tropical Lowland South America. Biotropica, v. 7, p. 141-61, 1975.

- Fluctuación vegetal y adaptación cultural prehistórica en Amazonia: algumas correlaciones tentativas. Relaciones, Buenos Aires, n. 10, p. 11-26, 1976.

Arqueological and Ethnographic evidence compatible with the model of forest fragmentation. In: PRACE, Gillean T. (Ed.). Biological Diversification in the Tropics. New York: Columbia University Press, 1982. p. 483-96. 
MEGGERS, Betty J. Advances in Brazilian Archaeology, 1935-1985. American Antiquity, v. 50 , n. 2 , p. $364-73,1985$.

MEGGERS, Betty J.; EVANS, Clifford. Archaeological Investigations at the Mouth of the Amazon. Washington, Smithsonian Institution. 1957.

. Lowland South America and the Antilles. In: JENNINGS, D. (Ed.). Ancient Native Americans. San Francisco: W. H. Freeman, 1978. p. 543-91.

MEGGERS, Betty J.; DIAS, Ondemar; MILLER, Eurico Th.; PEROTA, Celso. Implications of Archaeological Distributions in Amazonia. Separata dos Anais da Academia Brasileira de Ciências, p. 275-294. 1988.

MELIA, Bartomeu. El "modo de ser" Guaraní en la primera documentación jesuitica (1594-1639). Revista de Antropologia, São Paulo, v. 24, p. 1-24, 1981.

- La tierra sin mal de los Guaraní. Economía y profecía. Suplemento Antropológico del Ateneo Paraguayo, Asunción, v. 22, n. 2, p. 81-97, 1987.

MELIA, Bartomeu; SAUL, Marcos V. A.; MURARO, Valmir. O Guarani. Uma Bibliografia Etnológica. Santo Ângelo: Fundação Nacional pró-Memória/FUNDAMES. 1987.

MÉTRAUX, Alfred. Migrations historiques des Tupi-guarani. Joumal de la Societé de Américanistes, Paris, n. 19, p. 145, 1927.

. La Civilisation Matérielle des Tribus Tupi-guarani. Paris: Librarie Orientaliste. 1928.

- The Guarani. In: STEWARD, Julian (Ed.). Hadbook of South American Indians, Washington: Smithsonian Instituion, v. 3, p. 69-94, 1948.

. The Tupinamba. In: STEWARD, Julian (Ed.). Handbook of South American Indians, Washington: Smithsonian Instituion, v. 3, p. 95-133, 1948.

MIGLIAZZA, Ernest. Linguistic prehistory and the refuge model in Amazonia. In: PRANCE, Gillean T. (Ed.). Biological Diversification in the Tropics. New York: Columbia University Press, 1982. p. 497-519.

MORAN, Emilio F. A ecologia humana das populações da Amazônia. Petrópolis: Vozes, 1990.

MYERS, Thomas. Sarayacu: Ethnohistorical and Archaeological Investigations of a Nineteenthcentury Franciscan Mission in the Peruvian Montaña. Lincoln, University of Nebraska Studies. 1990.

NETTO, Ladislau. Investigaçôes sobre Archeologia Brazileira. Archivos do Museo Nacional do Rio de Janeiro, Rio de Janeiro, v. 6, p. 257-554, 1885.

NIMUENDAJÚ, Curt U. Die Sagen von der Erschaffung and Vernichtung der Welt als Grundlagen der Religion der Apapocuva-Guarani. Zeitschrift für Ethnologie, Berlin, v. 46, p. 284-403, 1914.

- Mapa Etno-Histórico de Curt Nimuendajú, Rio de Janeiro: IBGE/FUNDAÇÃO NACIONAL PRÓ-MEMÓRIA. 1981.

NOELLI, Francisco S. Por uma revisão da "busca da terra sem mal" dos Tupi. Boletim da $A B A$, v. 20, p. 16, dezembro, 1993a.

. Sem Tekohá não há Tekó (Em busca de um modelo etnoarqueológico da subsistência e da aldeia Guarani aplicado a uma área de domínio no delta do Jacul-RS). Porto Alegre: PUCRS, 1993b. (Dissertação de mestrado).

- A fossilização de uma visão acadêmica: o desenvolvimento e a manutenção da produção científica de Betty J. Maggers (1948-1993). s.d. (manuscrito)

PORRO, Antônio. As crônicas do Rio Amazonas. Notas etno-históricas sobre as antigas populações indígenas da Amazônia. Petrópolis: Vozes, 1993. 
PRONAPA, Programa Nacional de Pesquisas Arqueológicas. Brazilian Archeology in 1968: An interim report on the National Program of Archeology Research - PRONAPA. American Antiquity, v. 35, n. 1, p. 1-23, 1970.

QUEIROZ, Maria I. P. O mito da terra sem males: uma utopia Guarani? Revista de Cultura Vozes, Petrópolis, v. 67, n. 1, p. 41-50, 1973.

RIVET, Paul. Langues Américaines. III Langues de l'Amérique du sud et des Antilles. In: MEILLET, A. et COHEN, Marcel (Eds.). Les Langues du Monde. Collection Linguistique, Paris, Societé de Linguistique de Paris, v. 16, p. 639-717, 1924.

RODRIGUES, Aryon D. Fonética histórica Tupi-guarani: diferenças fonéticas entre o Tupi e o Guarani. Arquivo do Museu Paranaense, Curitiba, v. 4, p. 333-54, 1945.

. A nomenclatura na Familia Tupi-guarani. Boletín de Filología, Montevidéu, v. 6, n. 43 45, p. 98-104, 1950.

. Classification of Tupi-Guarani. International Journal of American Linguists, n. 24, p. 2314, 1958.

. A classificaçăo do Tronco Lingüístico Tupi. Revista de Antropologia, São Paulo, n. 12, p. 99-104, 1964.

- Evidences for Tupi-Carib relationship. In: KLEIN, H. \& STARK, L. (Es.). South American Indian Languages: Retrospect and Prospect. Austin: University of Texas Press, p. $371-404$, p. 1985.

. Linguas Brasileiras. São Paulo, Loyola, 1986.

ROOSEVELT, Anna C. Determinismo ecológico na interpretação do desenvolvimento social indígena da Amazônia. In: NEVES, Neves (Ed.). Origens, adaptaçōes e diversidade biológica do homem nativo da Amazônia. Belém: SCT/CNPq/MPEG. 1991a. p. 103-141.

. Moundbuilders of the Amazon. Nova York: Academic Press, $1991 \mathrm{~b}$.

- Arqueologia Amazônica. In: CUNHA, Manuela C. da (org.) Historia dos Índios no Brasil. São Paulo: FAPESP/SMC/Cia. das Letras. 1992. p. 53-86.

ROUSE, Irving. Arwakan Phylogeny, Caribbean Chronology, and their Implications for the Study of Population Moviment. (datilogr.). 1985.

SAHLINS, Marshall. Ihas de História. Rio de Janeiro, Jorge Zahar Editor. 1990.

SALZANO, Francisco M.; CALLEGARI-JACQUES, Sidia M. O índio da Amazônia: uma abordagem microevolucionária. In: NEVES, Walter (Ed.). Origens, adaptações e diversidade biológica do homem nativo da Amazônia. Belém: SCT/CNPq/MPEG. 1991. p. $39-45$.

SANTOS, Claristella A. Rotas de migração Tupiguarani - Analise das hipóteses. Recife: UFPE-CFC, 1991. (dissertação de mestrado).

- Mobilidade espaço-temporal da Tradição Tupiguarani: considerações lingüísticas e arqueológicas. Clio, série arqueológica, Recife, v. 1, n. 8, p. 89-130, 1992.

SCATAMACCHIA, Maria Cristina M. A tradição policrômica no leste da América do Sul evidenciada pela ocupação Guarani e Tupinambá: fontes arqueológicas e etno-históricas. Såo Paulo: USP, 1991. (Tese de doutorado).

SCHADEN, Egon. Ensaio Etno-sociológico sobre a mitologia heróica de algumas tribos indígenas do Brasil. Sociologia, v. 6, n. 4, p. 1-172, 1945.

- Aspectos fundamentais da cultura Guarani. São Paulo, Boletim da Faculdade de Filosofia, Ciências e Letras da USP, n. 188, 1954.

- A religião Guarani e o cristinianismo: contribuição ao estudo de um processo histórico de comunicação intercultural. Revista de Antropologia, São Paulo, v. 25, p. 1-24, 1982. 
SCHMIDT, Wilhelm. Kulturkreise und Kulturschichten in Sudamerika. Zeitschrift fur Ethnologie, Berlim, v. 45, p. 1014-130, 1913.

SCHMITZ. Pedro I. O Guarani no Rio Grande do Sul. Boletim do Marsul, Taquara, v. 2, p. $5-42,1985$.

- Migrantes da Amazônia: a tradição Tupiguarani. Arqueologia do RS, Brasil Documentos, São Paulo, v. 5, n. 31-66, 1991.

SILVA, Fernando A.; MEGGERS, Betty J. Cultural developmente in Brazil. In: MEGGERS, Betty and EVANS, Clifford (Eds.). Aboriginal Cultural Development in Latin America: an Interpretative Review. Washington: Smithsonian Institution, 1963. p. 119-129.

SPIX, Johan B. von; MARTIUNS, C. F. P. von. Reise in Brasilien, Muchen: Gedruckt her M. Lindauer, 1831.v. 1.

STEllA, Jorge B. As línguas indígenas da América. Revista do Instituto Historico e Geografico de São Paulo, São Paulo, v. 26, p. 5-172, 1928.

SUSNIK, Branislava. Dispersión Tupt-guaraní Prehistórica. Ensayo Analítico. Asunción: Museo Etnográfico "Andrés Barbero", 1975.

SWADESH, Morris. Glottochronology. In: FRIED, M. (org.). Readings in Anthropology. 2. ed. New York: Thomas Crowell, 1971. p. 384-403.

TERMINOLOGIA. Terminologia arqueológica brasileira para a cerâmica. Parte II. CEPA. Manuais de Arqueologia n. 1. Curitiba, UFPR. 8p. 1969.

. Terminologia arqueológica brasileira para a cerâmica. 2. ed. revista e ampliada. Cademos de Arqueologia, Curitiba, Centro de Ensino e Pesquisas Ar-queológicas, v. 1, n. 1, p. 119-48, 1976.

TORRES, Luis Maria. Los primitivos habitantes del delta del Paraná. Buenos Aires: Imprenta de Coni Hermanos, 1911.

. Relaciones arqueológicas de los pueblos del Amazonas. Actas y Trabajos Cientificos del XXV Congresso Internacional de Americanistas, Universidad Nacional de La Plata. Buenos Aires: Imprensa y Casa Editora "Coni", v. 2, p. 191-3, 1934.

URBAN, Greg. A história de cultura brasileira segundo as línguas nativas. In: CUNHA, Manuela Carneiro da (org.). História dos índios no Brasil. São Paulo, FAPESP/SMC/Cia. das Letras, 1992. p. 87-102.

VIVEIROS DE CASTRO, Eduardo B. Proposta para um II Encontro Tupi. Revista de Antropologia, São Paulo, n. 27-28, p. 403-8, 1984-1985.

VON DEN STEINEN, Karl. Durch Zentral-Brasilien. Expedition zur Erforschung des Schingú im Jahre 1884. Leipzig: F. A. Brockhaus, 1886.

WILLEY, Gordon. Ceramics. In: STEWARD, Julian (Ed.). Handbook of South American Indians, Washington: Smithsonian Institution, 1949. v. 5. p. 139-204.

WILlEY, Gordon R.; PHILLIPS, Phillip. Method and Theory in American Archaeology. Chicago: The University of Chicago Press, 1958. 